Please do not remove this page

RMIT

UNIVERSITY

\title{
The 12-month prevalence and nature of adverse experiences resulting in emergency medical presentations associated with the use of synthetic cannabinoid products
}

Winstock, Adam; Barratt, Monica

https://researchrepository.rmit.edu.au/esploro/outputs/9921861079301341/filesAndLinks?institution=61RMIT_INST\&index=null

Winstock, A., \& Barratt, M. (2013). The 12-month prevalence and nature of adverse experiences resulting in emergency medical presentations associated with the use of synthetic cannabinoid products. Human Psychopharmacology, 28(4), 390-393. https://doi.org/10.1002/hup.2292

Document Version: Accepted Manuscript

Published Version: https://doi.org/10.1002/hup.2292

Repository homepage: https://researchrepository.rmit.edu.au

Copyright (C 2013 John Wiley \& Sons, Ltd

Downloaded On 2023/04/26 22:23:30 +1000

Please do not remove this page 
This is the peer reviewed version of the following article:

Winstock, A., \& Barratt, M. J. (2013). The 12-month prevalence and nature of adverse experiences resulting in emergency medical presentations associated with the use of synthetic cannabinoid products. Human Psychopharmacology, 28(4), 390-393.

which has been published in final form at https://doi.org/10.1002/hup.2292

This article may be used for non-commercial purposes in accordance with Wiley Terms and Conditions for Use of Self-Archived Versions.

(C) 2013. This manuscript version is made available under the CC-BY-NC-ND 4.0 license http://creativecommons.org/licenses/by-nc-nd/4.0/ 
The 12-month prevalence and nature of adverse experiences resulting in emergency medical presentations associated with the use of synthetic cannabinoid products

Running head: Adverse experiences with synthetic cannabinoids

Key Words: Synthetic cannabinoids, legal highs, cannabis, emergency, toxicity, herbal incense

Adam R. Winstock ${ }^{1,2}$

Monica J. Barratt 3

${ }^{1}$ Kings College London, London, United Kingdom.

${ }^{2}$ Global Drug Survey, London, United Kingdom.

${ }^{3}$ National Drug Research Institute, Curtin University, Melbourne, Australia.

Addictions CAG

SLAM NHS Trust and KCL

151 Blackfriars Road

London SE1 8EL

02032239400

adam.winstock@kcl.ac.uk 
Funding/Sponsors: None.

Word count body text (max 1500): 1864 
Abstract

Objective. A wide range of synthetic cannabinoid products have recently become available through the Internet and shop fronts across the globe. Concerns about the consequences of their use have been prompted with increasing reports of emergency department presentations. Methods. An anonymous global online survey was conducted using a research tool based on previous work done by the group. Data collection took place during a 4-week period at the end of 2011. Results. Among 950 last-year users, 23 (2.4\%) reported having sought emergency medical treatment following the use of a synthetic cannabinoid product. The most common presentations were panic and anxiety, followed by paranoia and breathing difficulties. Recent users who reported seeking emergency medical treatment were significantly younger (median age 20 years, IQR 18-22) than those who did not report seeking treatment (median age 23 years, IQR 19-28; Mann-Whitney test, $z=2.89, p=.004)$. Conclusions. Synthetic cannabinoid use appears to be associated with a high prevalence of adverse experiences among users, especially younger users. Further research is required to determine whether particular compounds carry a higher risk of harm than others and to assess potential consequences of longer term use.

Word count abstract (max 200): 193 


\section{Introduction}

Synthetic cannabinoid (SC) products have become widely promoted online and through shop fronts in many countries over the last few years. Recreational use of SC products was first reported in 2004, with initial increased use reported in 2008 in Europe (European Monitoring Centre for Drugs and Drug Addiction, 2010) and in 2010-11 in the USA (Wells and Ott, 2011), Australia (Warhaft 2011) and New Zealand (Schep et al., 2011). Although SCs are structurally dissimilar from $\Delta$-9tetrahydrocannabinol (THC), the principal cannabinoid found in cannabis, they produce a range of subjective effects that show marked similarity to traditional cannabis preparations. Over 400 different SCs have been identified to date, varying widely in potency, receptor activation and chemical structure. The products themselves consist of relatively inert herbal products to which potent SCs are applied, and have been known by a variety of brand names, including Spice, K2 and Kronic (Fattore and Fratta, 2011; Hudson and Ramsey, 2011; Vardakou et al., 2010).

The acute adverse symptoms that have been reported in association with the use of SC products are tachycardia, psychosis, agitation/irritation, panic/anxiety, vomiting, and seizures (Castellanos and Thornton, 2012; Fattore and Fratta, 2011; Hoyte et al., 2012; Wells and Ott, 2011). This information has been gleaned from small-sample case series (e.g., Cohen et al., 2012; Every-Palmer, 2011; Hurst et al., 2011; Mir et al., 2011; Schneir and Baumbacher, 2012), large-sample health administrative records of calls to poisons centres (Forrester et al., 2011; Hoyte et al., 2012), and surveys of SC users recruited from the general population (Barratt et al., in press; Vandrey et al., 2012). No studies have yet been published that assess the prevalence of serious 
adverse events among SC users. In this paper we present the largest self-report study to date describing the prevalence and nature of serious adverse events requiring emergency room treatment among a large international cohort of recent SC users.

\section{Method}

\subsection{Design}

An anonymous, online survey of drug and alcohol use was designed and conducted by Global Drug Survey (www.globaldrugsurvey.com/mixmag2012). In collaboration with the UK-based dance music magazine Mixmag and the Guardian newspaper, the survey was widely promoted through our media partner websites and social networking media such as Facebook and Twitter. Further information about the utility, validity, and limitations of the current methodology has been discussed elsewhere (Winstock et al., 2001; Winstock et al., 2012; Winstock et al., 2011b; Winstock et al., 2002). Ethical approval was received from the Joint South London and Maudsley and Institute of Psychiatry NHS Research Ethics Committee.

\subsection{Measures}

Demographics and prevalence of lifetime (ever used) and recent use (last year and number of days in the last month) of a large number of substances including SCs were collected. All last-year users were asked if they sought emergency medical treatment in the preceding 12 months in association with the use of SCs and if so by what route they had consumed the SC product. Respondents were asked to indicate which symptoms they had experienced from a pre-determined list extrapolated from the literature available at the time (see Table 1 for list). 


\subsection{Analysis}

The analysis primarily involved descriptive statistics. Chi squared analysis was conducted to determine whether there was any difference in the prevalence of seeking medical treatment between genders and those from the USA versus elsewhere, and a Mann-Whitney test determined whether treatment seekers were significantly older or younger. Due to the relatively low level of missing data, we used available-case analysis or case-wise deletion (including all cases with observed values on the variables included in any particular analysis). We have noted the valid total N after each statistic. All analyses were conducted using Stata 11 (College Station, TX).

\section{Results}

\subsection{Demographic profile of synthetic cannabinoid users}

A full analysis of the demographic and drug use characteristics of the sample is available elsewhere (Winstock and Barratt, in press). In brief, of the 14,966 participants who responded to the survey, 2,513 (16.8\%) reported ever having used SCs. Of these, $980(40.6 \%$ of 2,417$)$ reported use of SCs in the last 12 months. Recent SC users were predominantly male $(79.6 \%$ of 953$)$ with a median age of 23 years (IQR [interquartile range] 19-28) and mean age of 25.3 years (SD [standard deviation] 8.32, range $18-65, N=961)$. Half the sample $(49.3 \%, n=471$ ) were from the USA, a quarter reporting living in the UK $(26.6 \%, n=254)$ and the remaining quarter $(24.1 \%, n=230)$ came from a variety of other countries including Australia, New Zealand and Canada $(N=955)$. 


\subsection{Patterns of SC use}

Consistent with the emergent status of this drug, the median number of years since first use was 2 (IQR 1-3, range $1-8, N=883$ ). The majority of last-year SC users $(60.6 \%, N=904)$ did not report use of the drug within the last 30 days. Of the 356 who did report last month use, the median days of use in the past month was 3 (IQR $1-8)$, and $17(4.8 \%)$ reported daily use $(N=356)$.

\subsection{Prevalence of emergency medical treatment}

Of 950 recent users who responded to the question, 23 (2.4\%) reported having sought emergency medical treatment following the use of SCs. Of these 23, most ( $n=21 ; 91.3 \%)$ reported smoking SC while 2 reported oral administration. Recent users who reported seeking emergency medical treatment were significantly younger (median age 20 years, IQR 18-22) than those who did not report seeking treatment (median age 23 years, IQR 19-28; Mann-Whitney test, $z=2.89, p=.004$ ). The prevalence of treatment seeking among females (3.2\%) was not significantly greater than males (2.3\%; Pearson's $\left.\chi^{2}=.422, p=.516\right)$. The prevalence of treatment seeking among residents of the USA (3.0\%) was not significantly greater than among non-USA residents (1.8\%; Pearson's $\chi^{2}=1.49, p=.223$ ). The prevalence of treatment seeking among last-month users (2.6\%) was not significantly greater than those who reported use more than one month ago (2.5\%; Pearson's $\left.\chi^{2}=.008, p=.928\right)$. Of lastmonth users, both groups of respondents reported a median of 3 days of synthetic cannabinoid use in the last month. 


\subsection{Self-reported symptoms}

The most common presentations were panic and anxiety, followed by paranoia and breathing difficulties (see Table 1). The median number of symptoms reported was 5 (IQR 3-8; range 0-11). Two cases reported seeking medical help but did not list any symptoms. The existence of these cases may indicate that some symptoms of synthetic cannabinoid intoxication were not in the provided list.

[insert Table 1 here]

\section{Discussion}

Using the largest self-report study to date $(N=950)$ describing the prevalence and nature of serious adverse events from SCs, we found that 23 (2.4\%) reported having sought emergency medical treatment. The most common presentations were panic and anxiety, followed by paranoia and breathing difficulties. Symptoms reported by this sample were generally comparable with other published data, although 'chest pain', a symptom of tachycardia, was reported by less than half of the present sample whereas in other studies tachycardia is more commonly reported (e.g., Barratt et al., in press; Hoyte et al., 2012). While the most common acute adverse effects seen among cannabis users do show some overlap with those seen in the current study (e.g., panic, anxiety, paranoia and nausea), others (e.g., chest pain, sweatiness and extreme agitation) are less commonly reported.

Recent users who reported seeking emergency medical treatment were significantly younger than those who did not report seeking treatment. This finding matches Barratt et al. (in press) who found that younger SC users reported a greater number 
of side effects from SC use than older SC users, and is also similar to findings from studies exploring the adverse effects of traditional cannabis intoxication (Smith 1968; Thomas 1993; Weil 1970).

We suggest that one in forty users of synthetic cannabinoid products seeking emergency medical treatment in the last 12 months represents a far higher rate than might be expected from a similar cohort of cannabis users. It is unfortunate that the current study did not ask an equivalent question of last-year cannabis users. To our knowledge last 12-month prevalence of seeking emergency medical treatment among cannabis users does not exist. Most work on the adverse effects of cannabis has focused on the association with longer term use and the development of psychiatric morbidity (e.g., Zammit et al., 2008; Degenhardt et al., 2003; Crippa et al., 2009), but does not provide comparable data on acute intoxication effects. Indeed, acute intoxication effects are typically excluded from large general population epidemiological studies so as not to interfere with diagnostic accuracy (van Os et al., 2002; Tien et al., 1990). In our other analysis, also from the current study (Winstock and Barratt, in press), SC products were perceived by users as producing more negative effects and greater paranoia compared with traditional cannabis. While this finding lends support to our proposition that synthetic cannabinoids carry a higher risk of acute harms compared with traditional cannabis, more research using comparable measures on both synthetic and traditional cannabis is needed.

\subsection{Limitations}

Anonymous online surveys have become increasingly utilised as a method of accessing large populations of drug users (Miller and Sønderlund, 2010). Although 
we have previously shown that such approaches may be a valid and effective tool for describing the effect profile of novel drugs (Winstock et al., 2011a; Winstock et al., 2002), these methods have significant limitations when judged against traditional epidemiological criteria. These limitations have been fully discussed in other papers (McCambridge et al., 2005a; McCambridge et al., 2005b; Winstock et al., 2001; Winstock et al., 2012; Winstock et al., 2011b). Nevertheless, in the early stages of the appearance of a new drug, rapid large population studies are a useful tool to determine the risk of serious adverse effects associated with the use of a substance, especially when triangulated with other information from health providers, law enforcement and basic scientists. Integrated analysis of data from these multiple sources may enable governments to develop and implement optimal public health strategies to address the appearance of these drugs.

Our study is also limited because there is no way of confirming the composition of the different products consumed nor whether the adverse response was related to dose, pre-existing disorders, or concurrent use of other drugs. Furthermore, we did not ask about the duration of the adverse experience nor did we ask about seizures as they have only recently been associated with SC intoxication (e.g., de Havenon et al., 2011; Schneir and Baumbacher, 2012). This study is also limited by the selfreport nature of responses, which could not be verified by health-care providers. 


\subsection{Conclusion}

The 12-month prevalence of unwanted adverse effects experienced by recent users of SCs is much higher than might be expected from those using traditional cannabis preparations. The findings are all the more worrying given the younger age of those reporting problems. Perhaps the most effective public health approach to addressing a class of compounds which are likely to remain widely available is increasing awareness of the less desirable effect profile and risks of increased anxiety and agitation associated with SC use.

\section{Conflict of interest}

Adam Winstock is founder and director of Global Drug Survey Ltd an independent data exchange hub. 
References

Barratt MJ, Cakic V, Lenton S. In press. Patterns of synthetic cannabinoid use in Australia. Drug Alc Rev

Castellanos D, Thornton G. 2012. Synthetic cannabinoid use: recognition and management. J Psychiatr Pract 18: 86-93.

Crippa JA, Zuardi AW, Martín-Santos R, et al. 2009. Cannabis and anxiety: a critical review of the evidence. Hum Psychopharmacol 24: 515-523.

Cohen J, Morrison S, Greenberg J, et al. 2012. Clinical presentation of intoxication due to synthetic cannabinoids. Pediatrics 129: e1064-e1067.

de Havenon A, Chin B, Thomas KC, et al. 2011. The secret "spice": an undetectable toxic cause of seizure. The Neurohospitalist 1: 182-186.

Degenhardt L, Hall W, Lynskey M. 2003. Exploring the association between cannabis use and depression. Addiction 98: 1493-1504.

European Monitoring Centre for Drugs and Drug Addiction, 2010. 2010 Annual report on the state of the drugs problem in Europe. EMCDDA, Luxembourg.

Every-Palmer S. 2011. Synthetic cannabinoid JWH-018 and psychosis: an explorative study. Drug Alcohol Depend 117: 152-157.

Fattore L, Fratta W. 2011. Beyond THC: the new generation of cannabinoid designer drugs. Front Behav Neurosci 5: Article 60.

Forrester MB, Kleinschmidt K, Schwarz E, et al. 2011. Synthetic cannabinoid exposures reported to Texas Poison Centers. J Addict Dis 30: 351-358.

Hoyte CO, Jacob J, Monte AA, et al. 2012. A characterization of synthetic cannabinoid exposures reported to the National Poison Data System in 2010. Ann Emerg Med 60: 435-438.

Hudson S, Ramsey J. 2011. The emergence and analysis of synthetic cannabinoids. Drug Test Anal 3: 466-478.

Hurst D, Loeffler G, McLay R. 2011. Psychosis associated with synthetic cannabinoid agonists: a case series. Am J Psychiatry 168: 1119.

McCambridge J, Hunt N, Winstock A, et al. 2005a. Has there been a decline in the prevalence of cannabis use among British nightclubbers? Five-year survey data. Drugs: Education, Prevention and Policy 12: 167-169. 
McCambridge J, Mitcheson L, Winstock A, et al. 2005b. Five-year trends in patterns of drug use among people who use stimulants in dance contexts in the United Kingdom. Addiction 100: 1140-1149.

Miller PG, Sønderlund AL. 2010. Using the internet to research hidden populations of illicit drug users: a review. Addiction 105: 1557-1567.

Mir A, Obafemi A, Young A, et al. 2011. Myocardial infarction associated with use of the synthetic cannabinoid K2. Pediatrics 128: e1622-e1627.

Schep LJ, Slaughter RJ, Temple WA, et al. 2011. Synthetic cannabinoid analoguesnot repeating past mistakes. $N$ Z Med J 124: 85-86.

Schneir AB, Baumbacher T. 2012. Convulsions associated with the use of a synthetic cannabinoid product. J Med Toxicol 8: 62-64.

Smith DE. 1968. Acute and chronic toxicity of marijuana. J Psychedelic Drugs 2: 3747.

Thomas H. 1993. Psychiatric symptoms in cannabis users. Br J Psychiatry 163: 141149.

Tien AY, Anthony JC. 1990. Epidemiological analysis of alcohol and drug use as risk factors for psychotic experiences. J Nerv Ment Dis 178: 473-480.

van Os J, Bak M, Hanssen M, et al. 2002. Cannabis use and psychosis: a longitudinal population-based study. Am J Epidemiol 156: 319-327.

Vandrey R, Dunn KE, Fry JA, et al. 2012. A survey study to characterize use of Spice products (synthetic cannabinoids). Drug Alcohol Depend 120: 238-241.

Vardakou I, Pistos C, Spiliopoulou C. 2010. Spice drugs as a new trend: mode of action, identification and legislation. Toxicol Lett 197: 157-162.

Warhaft G. 2011. Not for human consumption? The banning of synthetic cannabinoids. Of Substance 9: 14-17.

Wells DL, Ott CA. 2011. The "new" marijuana. Ann Pharmacother 45: 414-417.

Weil AT. 1970. Adverse reactions to marihuana. N Engl J Med 282: 997-1000.

Winstock AR, Barratt MJ. In press. Synthetic cannabis: a comparison of patterns of use and effect profile with natural cannabis in a large global sample. Drug Alcohol Depend

Winstock A, Mitcheson L, Ramsey J, et al. 2011a. Mephedrone: use, subjective effects and health risks. Addiction 106: 1991-1996. 
Winstock AR, Griffiths P, Stewart D. 2001. Drugs and the dance music scene: a survey of current drug use patterns among a sample of dance music enthusiasts in the UK. Drug Alcohol Depend 64: 9-17.

Winstock AR, Mitcheson L, Gillatt DA, et al. 2012. The prevalence and natural history of urinary symptoms among recreational ketamine users. BJU Int 110: 1762-1766.

Winstock AR, Mitcheson LR, Deluca P, et al. 2011b. Mephedrone, new kid for the chop? Addiction 106: 154-161.

Winstock AR, Wolff K, Ramsey J. 2002. 4-MTA: a new synthetic drug on the dance scene. Drug Alcohol Depend 67: 111-115.

Zammit S, Moore TH, Lingford-Hughes A, et al. 2008. Effects of cannabis use on outcomes of psychotic disorders: systematic review. Br J Psychiatry 193: 357-363. 
Table 1. Symptoms reported among those seeking emergency medical treatment following the use of SCs $(n=23)$

\begin{tabular}{|c|c|c|}
\hline Symptom & $n$ & $\%$ \\
\hline Panic and anxiety & 19 & 82.6 \\
\hline Paranoia & 13 & 56.5 \\
\hline Breathing difficulties & 13 & 56.5 \\
\hline Feeling very scared & 12 & 52.2 \\
\hline Very sweaty & 12 & 52.2 \\
\hline Chest pain & 10 & 43.5 \\
\hline Seeing things & 11 & 47.8 \\
\hline Unable to talk & 9 & 39.1 \\
\hline Extreme agitation & 8 & 34.8 \\
\hline Hearing things & 7 & 30.4 \\
\hline Aggression & 4 & 17.4 \\
\hline None reported & 2 & 8.7 \\
\hline
\end{tabular}

